\title{
Reduplication in Itawes
}

Laurel MacKenzie, University of Pennsylvania

\section{Introduction}

This paper examines reduplication in Itawes (also known as Itawit or Itawis), an Austronesian language spoken by approximately 100,000 people in Luzon, the northernmost island of the Philippines (Lewis, 2009). In addition to providing the first overview of reduplication in this little-studied language $(\{2,3)$, I examine the interactions between reduplication and three phonological processes: Vowel Laxing and Reduction ( $(4)$, and Glottal Stop Insertion ( 5 ). Though I do not argue for a particular phonological framework, my findings have implications for theories of consonant contact ( $(3)$ and of base-reduplicant correspondence ( $(4)$.

Data referenced in this paper come from a corpus of 309 reduplicated forms, derived from 150 unique bases. The informant is a female native speaker in her early 40s from the town of Tuao in the Cagayan Valley.

\section{Reduplicative Templates and their Distribution}

Reduplication in Itawes takes one light, one heavy, or two light syllables (i.e. a foot) from the left edge of the base, much like Ilokano (Hayes and Abad, 1989), though Ilokano has no reduplicants as large as a foot. The resulting reduplicant is prefixed to the base, inside any prefixes. Several reduplicative templates are available in Itawes, which may be paired with one of four different meanings: plurals of certain nouns and adjectives (1), augmentatives of adjectives (2), progressives (3), and recent pasts (4).

(1) kofun 'friend' ko-kofun 'friends'

mad-dana 'grows old' $\sim$ mad-dad-dana 'is growing old'
(2) na-rihat ${ }^{1}$ 'difficult' $\sim$ na-ri-rihat 'very difficult'

mal-laku 'sells' ka-la-laku 'just sold'

The reduplicative templates and the constraints on their use are as follows. The $\mathbf{C V}$ template is used with /h/-medial bases (5a) as well as to form plurals (5b); the $\mathbf{C V}+$ gemination (of the following, base-initial consonant) template is productive in heavy-syllable-initial bases $(6 a, b)$ and /h/-medial bases (6c); the CVC template is productive in light-syllable-initial bases (7a) and bases whose first syllable is closed by a geminate $(7 \mathrm{~b})$; the $\mathrm{CVC}(\mathrm{C}) \mathrm{V}$ template is productive in bases in which copied vowels are round $(8 a, b)$; and the CVC(C)a template is productive in light-syllable-initial bases (9a) and bases whose first syllable is closed by a geminate (9b).
a. bahu 'new' ba-bahu 'AUG'
b. tolay 'person' $\sim$ to-tolay 'PL'
a. mal-labbet 'arrives' $\sim$ mal-lal-labbet 'PROG'
b. pa?yit 'cheek(s)' pap-pa?yit 'PL'
c. na-daha 'bloody' $\sim$ na-dad-daha 'AUG'

\footnotetext{
${ }^{1} n a$ - and $m a C$ - are adjectival and verbal prefixes, respectively; they do not participate in reduplication.
} 
(7)
a. dusaru 'necklace' $\sim$ dus-dusaru 'PL'
b. bossot 'pot-bellied' $\sim$ bos-bossot 'AUG'

(9)
a. mag-gukud 'measures' mag-guku-gukud 'PROG'

b. bossot 'pot-bellied' $\sim$ boso-bossot, bosso-bossot 'AUG'

b. mak-kappil 'folds clothes' mak-kapa-kappil 'PROG'

Monosyllabic bases exceptionally include any prefix attached to the base in their reduplicant, which is then affixed outside of the prefix $(10 a, b)$.

$$
\begin{aligned}
& \text { a. na-ta 'unripe' } \sim \text { nat-na-ta 'AUG', } \\
& \text { *na-ta-ta }
\end{aligned}
$$
b. ma-yan 'eats' may-ma-yan 'PROG', *ma-yan-yan

\section{Reduplication and Consonant Contact}

The two heavy-syllable templates (CV+gem and CVC) are not equally productive among roots of different shapes. Specifically, CVCV bases strongly prefer CVC reduplicants (11) while $\mathrm{CVC}_{1} \mathrm{C}_{2} \mathrm{~V}$ bases strongly prefer $\mathrm{CV}+$ gem reduplicants (12). $\mathrm{CVC}_{1} \mathrm{C}_{1} \mathrm{~V}$ bases accept both reduplicants (13). There thus appears to be a tendency to avoid destruction of the consonant contact in $\mathrm{CVC}_{1} \mathrm{C}_{2} \mathrm{~V}$ bases, which is satisfied by avoiding the template that would take the first medial consonant but not the one adjacent to it. Instead, the CV+gem template, which takes neither medial consonant, is preferred. This constraint enforcing consonant contact preservation is presumably not operative in $\mathrm{CVC}_{1} \mathrm{C}_{1} \mathrm{~V}$ bases, whose two medal consonants are actually one set of consonant features spread over two slots, meaning that consonant contact is irrelevant; this explains the acceptability of the CVC template in such forms.

$$
\begin{aligned}
& \text { dana 'old' } \sim \text { dan-dana 'AUG', 'dad-dana } \\
& \text { na-kasta 'good' } \sim \text { na-kak-kasta' } A U G \text { ', 'na-kas-kasta }
\end{aligned}
$$

The bisyllabic (CVCV) template patterns like the CVC template: namely, it is almost categorically allowed by CVCV bases (14) and strongly dispreferred by $\mathrm{CVC}_{1} \mathrm{C}_{2} \mathrm{~V}$ bases (15). Like the CVC template, it is also acceptable with $\mathrm{CVC}_{1} \mathrm{C}_{1} \mathrm{~V}$ bases (16). Once again, this appears to reflect a constraint against separating two adjacent consonants in the base, a constraint that affects $\mathrm{CVC}_{1} \mathrm{C}_{2} \mathrm{~V}$ bases but not $\mathrm{CVC}_{1} \mathrm{C}_{1} \mathrm{~V}$ (or $\mathrm{CVCV}$ ) bases.

$$
\text { dana 'old' dana-dana 'AUG' }
$$

(16) na-bannag 'tired' $~ n a-b a n a-b a n n a g ~ ' A U G '$

Note, however, that onset clusters (in Spanish borrowings) are invariably simplified to conform to CV (17), CV+gem (18), CVC (19), and CVCa (20) templates. This provides evidence that what is exemplified in (11-16) is specifically a need to preserve syllable, and not simply consonant, contact in reduplication. Onset clusters, belonging to a single syllable, are thus not implicated and may be simplified, while clusters formed by consonants in adjacent syllables may not be. 
(17)

(19)

mag-graduar 'graduates' $~ k a-g a-g r a d u a r$ 'RECENT PAST'

$$
\text { gwapa 'cute' gap-gwapa 'AUG' }
$$

(18)

$$
\begin{aligned}
& \text { (18) freska 'fresh' } \sim \text { fef-freska 'AUG' } \\
& \text { (20) gwapa 'cute' } \sim \text { gapa-gwapa 'AUG' }
\end{aligned}
$$

Constraints on syllable contact in other languages typically refer to the sonority of the segments in the adjacent syllables in question (see, for instance, Bat-El (1996) and other work cited therein); Itawes, instead, constrains syllable contact on a more macro scale: regardless of consonant sonority, a syllable should not be taken as a reduplicant if the syllable it contacts in the base cannot be taken too.

\section{Reduplication and Vowel-Changing Processes}

Two allophonic processes interact differently with reduplication. One is a process laxing back vowels in closed syllables (21); the other reduces /a/ in unstressed syllables (22).

(21) Vowel Laxing: /o, $\mathrm{u} / \rightarrow[\mathrm{\jmath}, \mathrm{v}] / \mathrm{C}_{\sigma}$

(22) Vowel Reduction: /a/ $\rightarrow[ə] / \breve{\sigma}$

When Vowel Laxing applies to a base, its reduplicant matches it in vowel quality, regardless of the fact that this may result in a reduplicant with lax vowels in open syllables (23a) or tense vowels in closed syllables $(23 \mathrm{~b}, \mathrm{c})$. In other words, reduplicants match their bases in tenseness of $/ \mathrm{o} /$ and $/ \mathrm{u} /$, despite the fact that this tenseness may be opaque on the surface.

By contrast, where Vowel Reduction is concerned, reduplicants display the vowel quality expected on the surface, rather than that of their base. Thus, an unstressed syllable in a reduplicant whose corresponding base vowel was stressed will not match it in vowel quality $(24 a, b)$.
a. [bossot] 'potbellied' [bəso-bossst] 'AUG'
b. [bobo] 'dumb' $\sim$ [bob-bobo] 'AUG'
c. [nə-lutu] 'ripe' $\sim$ [nə-lut-lutu]

a. ['danə] 'old' [dənə-'danə] 'AUG'

b. [nə-bə'sa] 'wet' $\sim$ [nə-bəsə-bə'sa] 'AUG'

(23) and (24) illustrate that Vowel Laxing and Vowel Reduction differ crucially as far as base faithfulness is concerned. This could be accounted for in a serial theory by ordering Vowel Laxing before reduplication and Vowel Reduction afterward, or, in a constraint-based theory, by proposing an IDENT-BR constraint (McCarthy and Prince, 1995) that enforces faithfulness to tenseness only.

\section{Reduplication and Glottal Stop Insertion}

A third phonological rule inserts a glottal stop before a word-initial vowel (25).

$$
\text { Glottal Stop Insertion: } \varnothing \rightarrow ? \text { / \#__V }
$$

A small class of adjectives shows an interaction between this rule and reduplication. The adjectives in this class are all /a/-initial; the majority are native words that describe physical properties: e.g. ababba 'short', ali?nak 'short', atainay 'tall', asillat 'narrow'. Each word in this class has two acceptable reduplicated forms with the CVC template: 
One in which the base is preceded by a glottal One in which the base is not preceded by a stop: glottal stop:

(26) /ababba/ [?əbəb'ba] 'short' /ab-ababba/ [,Pab?əbəb'ba] 'AUG'

(27) /ababba/ [?əbəb'ba] 'short' /ab-ababba/ [?ə,ba:bəb'ba] 'AUG'

Syllabification and lengthening under stress apply subsequently, to result in the different prosodic structures indicated in the transcriptions.

These facts lend themselves well to an analysis in which reduplication interacts with phonological rules at different levels, such as that of Inkelas and Zoll (2005). Under such an analysis, Glottal Stop Insertion applies variably at the stem level (to produce forms such as (26), where the glottal stop precedes the base) or the word level (to produce forms such as (27), where the glottal stop precedes only the reduplicant). Alternatively, it could be that the glottal stops before these vowel-initial bases are in fact phonemic, as they are in Hawaiian (Elbert and Pukui, 1979), and the variation observed in these reduplicative forms is the result of a change in these lexical items from initial phonemic glottal stops (which would reduplicate to forms such as (26)) to glottal stops that are inserted by rule word-initially (which would reduplicate to forms such as (27)).

\section{Conclusion}

This paper has provided the first overview and analysis of reduplication in Itawes and has documented the following phenomena:

- A resistance to destroying syllable contact when reduplicating

- Base-reduplicant identity that is dependent on the nature of the vowel-changing process (identity is preserved in cases of laxing but not in cases of reduction)

- A rule of Glottal Stop Insertion that variably applies at different levels, or, alternatively, evidence for a change in the underlying forms of words in a certain class

\section{References}

Bat-El, Outi. 1996. Selecting the best of the worst: the grammar of Hebrew blends. Phonology 13:283-328.

Elbert, Samuel H., and Mary Kawena Pukui. 1979. Hawaiian Grammar. The University Press of Hawaii.

Hayes, Bruce, and May Abad. 1989. Reduplication and syllabification in Ilokano. Lingua 77:331-374.

Inkelas, Sharon, and Cheryl Zoll. 2005. Reduplication: Doubling in Morphology. Cambridge University Press.

Lewis, M. Paul, ed. 2009. Ethnologue: Languages of the World, sixteenth edition. Dallas, Texas: SIL International. Online version: http:/ / www.ethnologue.com.

McCarthy, John, and Alan Prince. 1995. Faithfulness and reduplicative identity. Rutgers Optimality Archive 60-0000. http:// roa.rutgers.edu/view.php3?id=568. 